\title{
Marketing library instruction to adults
}

\section{By Patricia Weaver}

\section{Saint Joseph's personal approach to attracting students}

0 ffering library instruction not connected to a particular course can be like having a party to which nobody comes. Potential attendees often sign up for classes with the best of intentions; but as time passes, the classes seem to lose priority among the myriad of responsibilities and commitments that adult students must deal with on at daily basis.

Five years ago, the Francis A. Drexel Library at Saint Joseph's University (SJU) decided to offer two Electronic Database Sessions at the beginning of each semester for incoming MBA students in order to introduce them to the wide variety of electronic resources available in their subject area. Knowing that my potential audience consisted mainly of adults with hectic schedules, I decided to approach the task from the perspective of profit-conscious service organizations by: 1) advertising using a personal approach that places tangible value on the service being offered, 2) offering the service at convenient days and times, and 3) using good follow-up techniques to ensure that our "customers" followed through.

\section{A personal approach}

The Iniversity's Aclministrative Computing Department helped me merge a form letter with student name and address files so that a personalized letter could be created on university letterheacl for each new MBA student. In the letter. I informed students that since research plays a large role in their education at $\mathrm{SJU}$, our library offers special instruction sessions to acquaint them with the kinds of electronic resources relevant to their studies and to help take some of the mystery out of clatahase searching. Each letter was individually signed, which gave me the opportunity to be sure that the computer printed an appropriate greeting following the address.

\section{Convenience stressed}

Sessions were offered on nights when the largest number of students would be on campus. The 50-minute classes were scheduled one hour before most MBA classes began-or ten minutes after early evening classes ended-so that students didn't need to make a special trip to campus. In addition, the letter stated that I would remain in the library after each session to answer questions or help students begin using the equipment.

A llyer/reservation form that could be mailed or faxed to the library was enclosed with every letter. In acldition, the reference desk telephone number and my e-mail address were listed in the letter so that students could make reservations in the manner most convenient to them. (Most tended to call in or fax their responses.) The flyer was designed to contain relevant information from the letter that could be posted on a bulletin board or refrigerator to serve as a reminder. It also stated that space was limited for each class.

\section{Follow-up: The critical step}

One week before the session. postcards were sent to all registrants informing them that space had been reserved for them on the day and time shown on the carl. Our Registrar's Office 
prints mailing labels, so the cards did not have to be addressed by hand; but the task could be accomplished by a work study student.

\section{Results}

The efforts outlined above resulted in full attendance at every class. The few people who were kept from attending at the last minute always called to apologize, and those calls of ten resulted in appointments to pick up an information packet or receive a cuick demonstration at another time. In addition, people who were unable to attend the sessions on the scheduled dates often called for informaltion or a personal appointment. Some saved my letter and called months later to ask about attending a session or to talk to me when they had special research needs.

\section{(Web cont. from page 488)}

to review the section entitled "Bulletins" which consists of very current information related to the library: system related messages ("OVID will be down ..."), blurbs for new or featured library activities or events ("The library will host a reception in the History of Medicine ..."), and the like. It was felt that every clepartment might have notices to contribute or suggestions to make in this vein.

Everyone was requested to check their designated section at least every two weeks with some exceptions. Some areas such as the introductory text and the library's mission statement do not change often and $\mathrm{ko}$ not need to be constantly monitored. Everyone is, of course, welcome to look and comment on all sections of the page, but they will only be held accountable for their assigned areas.

\section{Keeping it current}

But someone still has to make the changes to the documents after the reviewers find problems or needed updates. For this purpose, we organized a committee of staff members who expressed an interest in working directly on the Web page. The chair of this committee functions as Webmaster, arbiter hypertextum, and is the coordinator for all editing changes to the page. For the time being, the associate director for technical services and systems acts as chair but this position will eventually be assumed by another staff member. Each person is trained in html if needed, given an html editor, and assigned certain sections of the palge as their
While this might seem like a lot of work, it is important to remember that once the system is set up, only minor changes need to be made each semester. Return on investment has been excellent in terms of establishing contact with students. good public relations, and quality service to students. The system can be used to increase attendance at any kind of training or instructional sessions for graduate students and professional programs held on campus. (Similar sessions were offered to new graduate arts and sciences students during the fall 1996 semester with equally good results.) Most important, the success of the classes helped convince aciministration that library instruction should be required for all new business majors. Such instruction was instituted at both undergraduate and graduate levels in fall 1996.

normal editing responsiloility. Some bassic UNIX command instruction is also usually necessary.

Each committee member has an inclividual account on the library INIX server with his or her own subdirectory for library html pages as well as access to the administrative account. As the Web page reviewers find pages that need updating or as new material is added, this information is passed on to the committee which clistributes it to the appropriate member. The files are then edited or created on the member's PC and then uploaded via ftp to the member's individual library directory. For security reasons, no one can log on as administrator. In orcler to get the files to the library's Web clirectory, members must first log on in a telnet session using their individual logins, change to administrator, and then copy the files from their home directories. The process looks cumbersome on paper but actually flows smoothly in practice, especially with a Windows ftp program. All committee members try to keep an updated set of all library pages in their own U NIX directories and on their PCs. Files can be ftped directly from the library directory to their personal computers without having to have administrative rights.

These procedures allow the library to perform the necessary maintenance to keep its homepage fresh and current without becoming an undue burden on any one person. They also provicle the added bonus of having the staff feel more involved in the Web page on a personal level, since most are participating in some way in its development and maintenance. 